\title{
Dental Anomalies in Chinese Children with Cleft Lip and Palate
}

\author{
Hai Ming Wong ${ }^{1 *}$, Moon Cheung Lai ${ }^{2}$ and Nigel Martyn King ${ }^{3}$
}

${ }^{1}$ Paediatric Dentistry, Faculty of Dentistry, The University of Hong Kong, Prince Philip Dental Hospital, 34 Hospital Road, Hong Kong SAR, China

${ }^{2}$ Formally Postgraduate Student in Paediatric Dentistry, Faculty of Dentistry, The University of Hong Kong

${ }^{3}$ School of Dentistry, Faculty of Medicine, Dentistry and Health Sciences, The University of Western Australia, Perth, Australia

\begin{abstract}
Background: The prevalence of dental anomalies in children with cleft lip and palate (CLP) has been said to be higher than in the normal children; however, such findings have not been expressed for different racial groups.

Aim: To determine the prevalence of anomalies in children with CLP and to ascertain if there were any differences between the prevalence figures for CLP and non-CLP children.

Design: This is a retrospective study looking at previously collected clinical records. The sample consisted of 231 pairs of age and gender matched CLP and non-CLP southern Chinese aged between 12 and 16 years. The dental records of the subjects were examined to gather data on anomalies of tooth number, size and shape.

Results: It was found that $57.6 \%$ of the CLP children had hypodontia, $10.0 \%$ hyperdontia, $8.7 \%$ taurodontism, $0.8 \%$ a double tooth, $1.30 \%$ dens evaginatus, and $42.4 \%$ had microdontia in the permanent dentition. The CLP subjects had a statistically higher prevalence of hypodontia $(p<0.001)$, supernumerary $(p<0.01)$ and microdontia $(p<0.001)$ than the non-CLP subjects. More CLP children, were found to have one to three types of anomalies, than the non-CLP children $(p<0.001)$.

Conclusion: This group of Chinese CLP children demonstrated a higher prevalence of dental anomalies than the non-CLP children.
\end{abstract}

\section{Introduction}

It has been reported that patients with cleft lip and palate (CLP) exhibit a higher frequency of dental anomalies than non-cleft subjects [1-7]. These dental anomalies can be numerical $[8,9]$ or morphological [10]. However, any association between dental anomalies and the presence of clefts is poorly understood. Nevertheless, a direct relationship between the cleft formation and formation of the teeth, irrespective of the genetic predisposition and severity of the cleft type (i.e. uni- or bi-lateral) has been identified [11]. The frequency of dental anomalies among CLP subjects has been found to be higher than in their siblings, and non-cleft subjects, which were similar [12]. While familial and sporadic cleft cases show no difference in frequency [13]. However, it is unclear if there is any variation based on the ethnicity.

Hypodontia is commonly found in CLP patients and the prevalence ranges from $31.5 \%$ to $45.9 \%$ [14-19]. The lateral incisor is more often missing in CLP than in non-CLP subjects [20]. No gender difference for the prevalence of hypodontia has been found in CLP subjects [21]. As expected more maxillary teeth than mandibular teeth have been reported missing and the cleft side is most frequently affected; whilst both sides are similarly affected in the mandible [16].

In the non-cleft region, the prevalence of hypodontia is reportedly higher in CLP than non-CLP subjects $[3,8,14,16,17,22,23,24]$. Although these results are from different populations, the common findings are that the permanent maxillary lateral incisors and the premolars on the non-cleft side, are the teeth that are predominately involved.

The incidence of supernumerary teeth is highest in subjects with isolated cleft lip and appears to decrease with the severity of the cleft [14]. The prevalence of supernumerary teeth ranges from $6.7 \%$ to $22.2 \%[16,17,19]$ which is higher than in non-cleft subjects [20]. There is a tendency for a supernumerary primary incisor to be succeeded by a supernumerary permanent incisor [25]. However, the supernumerary primary lateral incisor can be followed by agenesis of the permanent lateral, or a permanent lateral on either side of the cleft, or a supernumerary tooth [16].

Morphological anomalies are found more often in cleft than noncleft subjects $[2,8,10,14,15,26,27]$. The frequency of abnormally sized and shaped teeth in CLP subjects, ranges from $35.0 \%$ to $49.5 \%$ [14,17]. They may be incisal, conical or of an intermediate type [18]. These malformations of the teeth have been considered by many authors to be a microform of CLP presentation [28-30]. The reason for the diminutive teeth is unknown; however, surgery cannot be excluded as a possible aetiological factor.

Taurodontism was defined by Holt and Brook [31] as an increase in the pulp chamber at the expense of the root. It is usually more evident in the mandibular molars and the prevalence has been reported to be $28.9 \%$ [32]. The prevalence of taurodontism in Chinese subjects is reportedly $65 \%$ in females and $36 \%$ in males [33]. Taurodontism has seldom been investigated in CLP subjects. Akcam and colleagues [34] reported that $1.9 \%$ of the unilateral cleft lip and palate children had taurodontic molars.

Double tooth is the anomaly of conjoined teeth, which includes both fusion and germination [35]. The location is commonly unilateral in the mandibular lateral incisor region [35-41]. Fusion is said to be more common than germination $[36,37,39,40,42-44]$. The prevalence of this anomaly in CLP children has been reported by Pöyry and Ranta [45], who found it to be lower than in the non-CLP subjects.

Dens evaginatus is a rare developmental anomaly that is predominately found in mongoloid races with a prevalence of $0.1 \%$ to $6.3 \%$ [46-48]. The corresponding figure for CLP subjects has been reported to be lower than other dental anomalies [34]. Interestingly

*Corresponding author: Hai Ming Wong, Department of Paediatric Dentistry, Faculty of Dentistry, The University of Hong Kong, Floor 2A, The Prince Philip Dental Hospital, 34 Hospital Road, Hong Kong, Tel: +852 2859 0261; Fax: +852 2559 3803; E-mail: wonghmg@hkucc.hku.hk

Received December 19, 2011; Accepted March 26, 2012; Published March 28 2012

Citation: Wong HM, Lai MC, King NM (2012) Dental Anomalies in Chinese Children with Cleft Lip and Palate. Dentistry 2:127. doi:10.4172/2161-1122.1000127

Copyright: @ 2012 Wong HM, et al. This is an open-access article distributed under the terms of the Creative Commons Attribution License, which permits unrestricted use, distribution, and reproduction in any medium, provided the original author and source are credited. 
Citation: Wong HM, Lai MC, King NM (2012) Dental Anomalies in Chinese Children with Cleft Lip and Palate. Dentistry 2:127. doi:10.4172/21611122.1000127

Page 2 of 8

according to Yumikura and Yoshida [49], 42\% of evaginations can be expected to contain pulp tissue. Consequently, periapical abscesses can occur on caries free teeth if the tubercle is fractured [50-56].

Although most types of dental anomalies have been studied in CLP subjects, they have never been considered in a Chinese population. Thus the aim of this study was to investigate the prevalence of the various types of dental anomalies in southern Chinese children with CLP and to compare the results with an age and gender matched group of non-cleft children.

\section{Materials and Methods}

The investigation was based on a sample of southern Chinese CLP children living in Hong Kong. The sample was drawn from children registered at the only dental hospital in Hong Kong, the Prince Philip Dental Hospital in which the first Cleft Lip and Palate Centre in Hong Kong was established. The CLP patients of the centre came from a variety of sources including "walk-in" patients and referrals from Government Hospitals, private medical and dental practitioners. Approval to conduct this study was received from the Ethics Committee of the Faculty of Dentistry, the University of Hong Kong.

The host computer of the dental hospital was used to establish a sample of 548 CLP subjects of which 531 were of southern Chinese origin. The subjects with poor quality radiographic records or study casts, associated syndromes, or relevant medical diseases were excluded from the study. Thus, the final CLP group consisted of 231 children with ages that ranged from 12 to 16 years (mean age $=13.8$ years).

A control group of non-CLP subjects was then randomly selected, using the same hospital host computer, so as to be gender matched to the CLP subjects. The exclusion criteria were the same as those of the CLP subjects except that children receiving orthodontic treatment were excluded. In addition, the non-CLP subjects were selected so that their ages and the date of panoramic radiographs matched, within 30 days, to those of the CLP subjects. This resulted in a total of 231 children without CLP who were age and gender matched with the 231 children with CLP.

In addition to studying the study casts, and medical and dental records of each CLP and non-CLP subjects, the panoramic, upper anterior occusal and periapical radiographs taken during the entire period of treatment were thoroughly examined in a darkened room using an illuminated $\mathrm{x}$-ray viewing box. Study casts (12 years) and panoramic radiographs exhibiting the early ( $6-7$ years) and late mixed dentitions (11 - 12 years) were available for every subject.

A pilot study was conducted prior to the main study to test the feasibility of the computer program to be used for data entry, and to calibrate and train the investigator with the indexes and criteria for diagnosing and recording the observations. The dental records of 40 CLP children were randomly selected from the excluded patients for the pilot study.

In the main study, the dental history and radiographs of each CLP subject were studied carefully for the type of cleft in CLP subjects which was classified according to the extent of the cleft involvement of the three anatomical structures; the lip, alveolus and palate. The clefts were classified as:

i. $\quad$ isolated cleft lip only (CL)

ii. complete bilateral cleft lip, alveolus, and palate (BCLP)

iii. left or right, complete unilateral cleft lip, alveolus, and palate (L-CLP or R-CLP) iv. isolated cleft palate only (CP)

The FDI index of tooth notation was used to identify teeth. The following criteria were employed to diagnose six dental anomalies in the permanent dentition:

\section{i. Hypodontia}

One or more congenitally missing teeth. Supported by a dental history to determine if previous extraction had been performed.

\section{ii. Supernumerary}

Any additional tooth in excess of the usual number for a given region of the dentition. The type of a supernumerary tooth was recorded according to the criteria of Primosch [57]. In cases where a tooth adjacent to the cleft could not be differentiated as being a supernumerary or a permanent lateral, it was recorded as being a permanent lateral incisor if no other tooth germ existed in the same region. Otherwise, the tooth was recorded as a supernumerary tooth.

\section{iii. Taurodontism}

When the ratio between the vertical distances from the amelocemental junction to the floor of the pulp chamber, and the amelocemental junction to the apex of the roots of the mandibular first molar, was 1:4.5 or less [31].

iv. Double tooth

Notching of the incisal edge and bifurcation of the pulp system.

\section{v. Dens evaginatus}

An enamel tubercle on the occlusal surface between the buccal and lingual cusps in a premolar.

\section{vi. Microdontia}

Teeth of a size smaller than 2.0 SD from the mean were considered to be abnormal. The mean size of teeth in southern Chinese was adopted from the studies of Ling [58].

\section{Statistical analysis}

The data were analyzed using the SAS statistical software package. The results included descriptive statistics of each dental anomaly and test statistics (Chi-square) were calculated if necessary. The records of $10 \%$ of the CLP subjects were randomly selected for re-examination in order to test the reproducibility of the results. The Kappa coefficient (к) was used to measure the intra-examiner reproducibility as recommended by Landis and Koch [59].

\section{Results}

\section{Epidemiology}

The gender distribution for each cleft type in the CLP group is shown in Table 1 . Of the 231 CLP children, 123 (53.2\%) were males and $108(46.8 \%)$ females. The most common cleft type was L-UCLP which occurred in 103 (44.6\%) children.

\section{Various types of anomalies}

The Kappa coefficients for the diagnoses of dental anomalies of each tooth ranged from 0.93 to 1.00 . The level of agreement was therefore either "almost perfect" or "total agreement", indicating that the reproducibility of the diagnosis was highly accurate. The most common dental anomalies in the permanent dentitions of CLP children were 
hypodontia (57.6\%) and microdontia (42.4\%), see Table 2. The CLP subjects had a statistically higher prevalence of hypodontia $(p<0.001)$, supernumerary teeth $(p<0.01)$ and microdontia $(p<0.001)$ than the non-CLP subjects. Although taurodontism and dens evaginatus were more prevalent in the CLP children than the non-CLP children, the differences were not statistically significant. For the various types of CLP, hypodontia was the dominant dental anomaly in the BCLP children at $71.8 \%$ (Table 3 ).

\section{Number of types of dental anomalies per individual}

Of the 231 non-CLP children, 200 (86.6\%) had no dental anomalies while this occurred in only $28(12.1 \%)$ of the CLP children $(p<0.001)$, see Table 4. More CLP children were found to have one to three different types of anomalies than the non-CLP children $(p<0.001)$. Most of the CLP children had only one type of dental anomaly (41.6\%).

\begin{tabular}{|l|c|c|c|c|c|c|}
\hline \multirow{2}{*}{ Cleft type } & \multicolumn{2}{|c|}{ Male } & \multicolumn{2}{c|}{ Female } & \multicolumn{2}{c|}{ Male + Female } \\
\cline { 2 - 7 } & $\mathbf{n}$ & $\%$ & $\mathbf{n}$ & $\%$ & $\mathbf{n}$ & $\%$ \\
\hline CL & 5 & 2.2 & 3 & 1.3 & 8 & 3.5 \\
\hline BCLP & 24 & 10.4 & 15 & 6.5 & 39 & 16.9 \\
\hline L-UCLP & 48 & 20.8 & 55 & 23.8 & 103 & 44.6 \\
\hline R-UCLP & 32 & 13.8 & 21 & 9.1 & 53 & 22.9 \\
\hline CP & 14 & 6.1 & 14 & 6.1 & 28 & 12.1 \\
\hline All cleft types & 123 & 53.2 & 108 & 46.8 & 231 & 100.0 \\
\hline
\end{tabular}

CLP = cleft lip and palate

$\mathrm{CL}=$ isolated cleft lip only

$\mathrm{BCLP}=$ complete bilateral cleft lip, alveolus, and palate

L-UCLP = left side, complete unilateral cleft lip, alveolus, and palate

R-UCLP = right side, complete unilateral cleft lip, alveolus, and palate

$\mathrm{CP}=$ isolated cleft palate only.

Table 1: The number and percentage of the different types of CLP in 231 southern Chinese children.

\begin{tabular}{|l|c|c|c|c|c|}
\hline \multirow{2}{*}{ Anomaly } & \multicolumn{2}{|c|}{ CLP } & \multicolumn{2}{c|}{ non-CLP } & \multirow{2}{*}{$\boldsymbol{p}$-value } \\
\cline { 2 - 5 } & $\mathbf{n}$ & $\%$ & $\mathbf{n}$ & $\%$ & \\
\hline Hypodontia & 133 & 57.6 & 17 & 7.4 & $<0.001^{\text {**+ }}$ \\
\hline Supernumerary & 23 & 10.0 & 6 & 2.6 & $0.0017^{*+}$ \\
\hline Taurodontism & 20 & 8.7 & 10 & 4.3 & $0.088^{\mathrm{NS}}$ \\
\hline Double tooth & 1 & 0.4 & 1 & 0.4 & \\
\hline Dens evaginatus & 3 & 1.3 & 0 & 0 & $0.248^{\mathrm{NS}}$ \\
\hline Microdontia & 98 & 42.4 & 2 & 0.9 & $<0.001^{\text {**+ }}$ \\
\hline
\end{tabular}

CLP $=$ cleft lip and palate

${ }^{*}=p<0.05 ;{ }^{* *}=p<0.01 ;{ }^{* * *}=p<0.001 ; \mathrm{NS}=$ not significant

Table 2: The number and percentage of dental anomalies in 231 CLP and 231 non-CLP southern Chinese children

\begin{tabular}{|c|c|c|c|c|c|c|c|c|c|c|}
\hline \multirow{3}{*}{ Dental anomaly } & \multirow{2}{*}{\multicolumn{2}{|c|}{$\begin{array}{c}C L \\
(N=8)\end{array}$}} & \multirow{2}{*}{\multicolumn{2}{|c|}{$\begin{array}{l}\text { BCLP } \\
(\mathrm{N}=39)\end{array}$}} & \multirow{2}{*}{\multicolumn{2}{|c|}{$\begin{array}{l}\text { L-UCLP } \\
(\mathrm{N}=103)\end{array}$}} & \multirow{2}{*}{\multicolumn{2}{|c|}{$\begin{array}{c}\text { R-UCLP } \\
(\mathrm{N}=53)\end{array}$}} & \multirow{2}{*}{\multicolumn{2}{|c|}{$\begin{array}{c}C P \\
(N=28)\end{array}$}} \\
\hline & & & & & & & & & & \\
\hline & $\mathbf{n}$ & $\%$ & 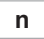 & $\%$ & $n$ & $\%$ & $\mathbf{n}$ & $\%$ & $\mathbf{n}$ & $\%$ \\
\hline Hypodontia & 3 & 37.5 & 28 & 71.8 & 61 & 59.2 & 31 & 58.5 & 9 & 32.1 \\
\hline Supernumerary & 2 & 25.0 & 3 & 7.7 & 12 & 11.7 & 6 & 11.3 & 0 & 0 \\
\hline Taurodontism & 0 & 0 & 4 & 10.3 & 10 & 9.7 & 5 & 9.4 & 1 & 11.1 \\
\hline Double tooth & 0 & 0 & 1 & 2.6 & 0 & 0 & 0 & 0 & 0 & 0 \\
\hline Dens evaginatus & 0 & 0 & 1 & 2.6 & 1 & 1.0 & 1 & 1.9 & 0 & 0 \\
\hline Microdontia & 2 & 25.0 & 18 & 46.2 & 54 & 52.4 & 22 & 41.5 & 2 & 22.2 \\
\hline
\end{tabular}

CLP = cleft lip and palate

$\mathrm{CL}=$ isolated cleft lip only

$\mathrm{BCLP}=$ complete bilateral cleft lip, alveolus, and palate

L-UCLP = left side, complete unilateral cleft lip, alveolus, and palate

$\mathrm{R}-\mathrm{UCLP}=$ right side, complete unilateral cleft lip, alveolus, and palate

$\mathrm{CP}=$ isolated cleft palate only.

Table 3: The number and percentage of dental anomalies in 231 CLP southern Chinese children.
The highest number of dental anomalies any one individual had was four for the CLP and two for the non-CLP children. The frequency of anomalies per individual for the different types of CLP are displayed in Table 5. Since there was no statistical difference in the prevalence figures in L-UCLP and R-UCLP groups, the data were pooled. The cleft types with four associated dental anomalies per individual were BCLP $(\mathrm{n}=3)$ and UCLP $(\mathrm{n}=1)$. All CL and BCLP children exhibited at least one type of anomaly.

\section{Number of teeth affected per individual}

Most of the CLP children had one tooth affected by an anomaly such as hypodontia, supernumerary, and microdontia; while in the case of taurodontism, two or four teeth were affected per person (Table 6).

\section{Hypodontia}

The cleft type associated with the highest percentage of missing teeth was BCLP (71.8\%), see Table 3. The frequency of hypodontia in the permanent dentition of the different types of CLP children is displayed in Table 7. There was no statistical difference in the prevalence figures for hypodontia in L-UCLP (59.2\%) and R-UCLP (58.5\%), see Table 3 , so the data were pooled for analysis. The most frequently missing tooth in the CLP children was the maxillary lateral incisor (Figure 1). It was most often missing in the children with UCLP (62.8\%) and BCLP (59.0\%). The most frequently missing tooth in the mandible was the second premolar and it was more often missing in the children with $\mathrm{CP}$ (46.4\%) and BCLP (23.1\%).

\section{Supernumerary teeth}

The cleft type associated with the highest percentage of supernumerary teeth was CL (25.0\%), see Table 3. By contrast no supernumerary teeth were found in the $\mathrm{CP}$ group. Of the 30 supernumerary that were identified in the CLP group, 27 (90\%) were located in the anterior region of the maxilla with sixteen (64\%) being in the cleft region. The predominant shape of supernumerary teeth

\begin{tabular}{|l|c|c|c|c|c|}
\hline \multirow{2}{*}{ Number of anomalies } & \multicolumn{2}{|c|}{ CLP } & \multicolumn{2}{c|}{ non-CLP } & \multirow{2}{*}{$\boldsymbol{p}$-value } \\
\cline { 2 - 6 } & $\mathbf{n}$ & $\%$ & $\mathbf{n}$ & $\%$ & \\
\hline $\mathbf{0}$ & 28 & 12.1 & 200 & 86.6 & $<0.001^{\text {**+ }}$ \\
\hline $\mathbf{1}$ & 96 & 41.6 & 26 & 11.2 & $<0.001^{*+*}$ \\
\hline $\mathbf{2}$ & 65 & 28.1 & 5 & 2.2 & $<0.001^{*+*+}$ \\
\hline $\mathbf{3}$ & 38 & 16.5 & 0 & 0 & $<0.001^{*+*}$ \\
\hline $\mathbf{4}$ & 4 & 1.7 & 0 & 0 & $0.123^{\mathrm{NS}}$ \\
\hline
\end{tabular}

$\mathrm{CLP}=$ cleft lip and palate.

*** $=p<0.001 ; \mathrm{NS}=$ not significant

Table 4: The frequency of anomalies per individual in 231 CLP and 231 non-CLP southern Chinese children.

\begin{tabular}{|l|c|c|c|c|c|c|c|c|}
\hline \multirow{2}{*}{$\begin{array}{l}\text { Number of } \\
\text { anomalies }\end{array}$} & \multicolumn{2}{|c|}{$\begin{array}{c}\text { CL } \\
(\mathbf{N}=\mathbf{8})\end{array}$} & \multicolumn{2}{c|}{$\begin{array}{c}\text { BCLP } \\
(\mathbf{N}=39)\end{array}$} & \multicolumn{2}{c|}{$\begin{array}{c}\text { UCLP } \\
(\mathbf{N}=156)\end{array}$} & \multicolumn{2}{c|}{$\begin{array}{c}\text { CP } \\
(\mathbf{N}=\mathbf{2 8})\end{array}$} \\
\cline { 2 - 9 } & $\mathrm{n}$ & $\%$ & $\mathrm{n}$ & $\%$ & $\mathrm{n}$ & $\%$ & $\mathrm{n}$ & $\%$ \\
\hline $\mathbf{0}$ & 0 & 0 & 0 & 0 & 9 & 5.8 & 19 & 67.9 \\
\hline $\mathbf{1}$ & 5 & 62.5 & 16 & 41.0 & 68 & 43.6 & 7 & 25.0 \\
\hline $\mathbf{2}$ & 1 & 12.5 & 10 & 25.6 & 52 & 33.3 & 2 & 7.1 \\
\hline $\mathbf{3}$ & 2 & 25.0 & 10 & 25.6 & 26 & 16.7 & 0 & 0 \\
\hline $\mathbf{4}$ & 0 & 0 & 3 & 7.8 & 1 & 0.6 & 0 & 0 \\
\hline
\end{tabular}

CLP = cleft lip and palate

$\mathrm{CL}=$ isolated cleft lip only

$\mathrm{BCLP}=$ complete bilateral cleft lip, alveolus, and palate

UCLP = complete unilateral cleft lip, alveolus, and palate

$\mathrm{CP}=$ isolated cleft palate only.

Table 5: The frequency of anomalies per individual in 231 CLP southern Chinese children. 
Citation: Wong HM, Lai MC, King NM (2012) Dental Anomalies in Chinese Children with Cleft Lip and Palate. Dentistry 2:127. doi:10.4172/21611122.1000127

Page 4 of 8

\begin{tabular}{|c|c|c|c|c|c|c|c|c|c|c|c|c|c|c|}
\hline \multirow{3}{*}{ Dental anomaly } & \multicolumn{14}{|c|}{ Number of teeth affected } \\
\hline & \multicolumn{2}{|c|}{0} & \multicolumn{2}{|c|}{1} & \multicolumn{2}{|c|}{2} & \multicolumn{2}{|c|}{3} & \multicolumn{2}{|c|}{4} & \multicolumn{2}{|l|}{5} & \multicolumn{2}{|c|}{$>5$} \\
\hline & $\mathrm{n}$ & $\%$ & $\mathrm{n}$ & $\%$ & $\mathrm{n}$ & $\%$ & $\mathrm{n}$ & $\%$ & $\mathbf{n}$ & $\%$ & $\mathbf{n}$ & $\%$ & $n$ & $\%$ \\
\hline Hypodontia & 98 & 42.4 & 75 & 32.5 & 30 & 13.0 & 7 & 3.0 & 9 & 3.9 & 2 & 0.9 & 10 & 4.3 \\
\hline Supernumerary & 208 & 90.0 & 21 & 9.1 & 1 & 0.4 & 1 & 0.4 & 0 & 0 & 0 & 0 & 0 & 0 \\
\hline Taurodontism & 211 & 91.3 & 0 & 0 & 9 & 3.9 & 0 & 0 & 11 & 4.8 & 0 & 0 & 0 & 0 \\
\hline Double tooth & 230 & 99.6 & 1 & 0.4 & 0 & 0 & 0 & 0 & 0 & 0 & 0 & 0 & 0 & 0 \\
\hline $\begin{array}{l}\text { Dens } \\
\text { evaginatus }\end{array}$ & 228 & 98.7 & 0 & 0 & 2 & 0.9 & 0 & 0 & 1 & 0.4 & 0 & 0 & 0 & 0 \\
\hline Microdontia & 133 & 57.6 & 91 & 39.4 & 7 & 3.0 & 0 & 0 & 0 & 0 & 0 & 0 & 0 & 0 \\
\hline
\end{tabular}

CLP = cleft lip and palate.

Table 6: The number and percentage of teeth per individual that were affected by dental anomalies in 231 CLP southern Chinese children.

\begin{tabular}{|c|c|c|c|c|c|c|c|c|}
\hline \multirow{2}{*}{ Type of tooth } & \multicolumn{2}{|c|}{$C L(N=8)$} & \multicolumn{2}{|c|}{ BCLP $(\mathrm{N}=39)$} & \multicolumn{2}{|c|}{ UCLP (N = 156) } & \multicolumn{2}{|c|}{$C P(N=28)$} \\
\hline & $\mathrm{n}$ & $\%$ & $\mathrm{n}$ & $\%$ & $\mathrm{n}$ & $\%$ & $\mathrm{n}$ & $\%$ \\
\hline \multicolumn{9}{|l|}{ Maxillary } \\
\hline Central incisor & 0 & 0 & 5 & 12.8 & 2 & 1.3 & 0 & 0 \\
\hline Lateral incisor & 2 & 25.0 & 23 & 59.0 & 98 & 62.8 & 8 & 28.6 \\
\hline Canine & 1 & 12.5 & 2 & 5.1 & 6 & 3.8 & 0 & 0 \\
\hline First premolar & 0 & 0 & 3 & 7.7 & 4 & 2.6 & 2 & 7.1 \\
\hline Second premolar & 0 & 0 & 14 & 35.9 & 19 & 12.2 & 3 & 10.7 \\
\hline First molar & 0 & 0 & 0 & 0 & 0 & 0 & 0 & 0 \\
\hline Second molar & 0 & 0 & 0 & 0 & 2 & 1.3 & 0 & 0 \\
\hline \multicolumn{9}{|l|}{ Mandibular } \\
\hline Central incisor & 0 & 0 & 2 & 5.1 & 4 & 2.6 & 2 & 7.1 \\
\hline Lateral incisor & 0 & 0 & 2 & 5.1 & 9 & 5.8 & 6 & 21.4 \\
\hline Canine & 0 & 0 & 0 & 0 & 1 & 0.6 & 0 & 0 \\
\hline First premolar & 0 & 0 & 5 & 12.8 & 0 & 0 & 1 & 3.6 \\
\hline Second premolar & 0 & 0 & 9 & 23.1 & 13 & 8.3 & 13 & 46.4 \\
\hline First molar & 0 & 0 & 0 & 0 & 0 & 0 & 0 & 0 \\
\hline Second molar & 0 & 0 & 0 & 0 & 1 & 0.6 & 0 & 0 \\
\hline
\end{tabular}

CLP = cleft lip and palate

$\mathrm{CL}=$ isolated cleft lip only

BCLP = complete bilateral cleft lip, alveolus, and palate

UCLP = complete unilateral cleft lip, alveolus, and palate

$\mathrm{CP}=$ isolated cleft palate only.

Table 7: The frequency of hypodontia in the permanent teeth of 231 CLP southern Chinese children.

was conical in $90 \%$ of the CLP (Figure 2) and $85.8 \%$ of the non-CLP children. Supernumerary teeth of supplemental type were found in two children (6.7\%) of the CLP group and one (14.2\%) of the non-CLP group. One subject (3.3\%) in the CLP group had supernumerary tooth of tuberculate shape. No molariform supernumeraries were found in this study.

\section{Taurodontism}

Approximately $10 \%$ of BCLP, UCLP and CP children were found to have taurodontism (Table 3). Forty nine out of 924 (5.3\%) of the first molars in the CLP children exhibited taurodontism while the corresponding figure for the non-CLP children was lower at $2.7 \%$ (25/924). For the CLP children, 65\% (32/49) of the teeth that exhibited taurodontism were the maxillary first molars (Figure 3 ).

\section{Double tooth}

Double tooth was found in only one child with BCLP (Table 3 ) and it was located in the mandibular left incisor region (Figure 4). In this case the canine in the same quadrant was present.

\section{Dens evaginatus}

Only three (1.3\%) of the CLP children had dens evaginatus on their premolars (Figure 5). None of the non-CLP children had this anomaly (Table 2).

\section{Microdontia}

Microdontia was found in $42.4 \%$ of the CLP group and most of them were children with L-UCLP (Tables 2 and 3). Microdontic teeth in the CLP subjects, as demonstrated by the presence of peg-shaped lateral incisors in the cleft region, had a prevalence of $78.3 \%(90 / 115)$. In the non-cleft region of the CLP children, 8 lateral incisors, 12 premolars (Figure 6) and 5 central incisors were found to be microdontic. Only two microdontic teeth were found in the non-CLP children $(p<0.001)$. Microdontia occurred predominantly in the children with clefts involving the lip and palate; for example, $46.2 \%$ (18/39) and $45.8 \%$ $(76 / 166)$ of the children with BCLP and UCLP, respectively.

\section{Discussion}

As this retrospective study was based on the southern Chinese children registered in a dental hospital the sample data can be considered to be biased to a certain extent though children receiving orthodontic treatment were excluded from the non-CLP group. The collected data will still be useful for future meta-analysis studies. The male to female ratio for CLP in this study was in accordance with most 
Citation: Wong HM, Lai MC, King NM (2012) Dental Anomalies in Chinese Children with Cleft Lip and Palate. Dentistry 2:127. doi:10.4172/21611122.1000127

\begin{tabular}{|l|c|c|c|c|c|c|c|c|}
\hline \multirow{2}{*}{ Tooth } & \multicolumn{2}{|c|}{$\begin{array}{c}\text { CL } \\
(\mathbf{N}=\mathbf{8})\end{array}$} & \multicolumn{2}{c|}{$\begin{array}{c}\text { BCLP } \\
\text { (N=39) }\end{array}$} & \multicolumn{2}{c|}{$\begin{array}{c}\text { L-UCLP } \\
\text { (N=103) }\end{array}$} & \multicolumn{2}{c|}{$\begin{array}{c}\text { R-UCLP } \\
\text { (N = 53) }\end{array}$} \\
\cline { 2 - 9 } & $\mathrm{n}$ & $\%$ & $\mathrm{n}$ & $\%$ & $\mathrm{n}$ & $\%$ & $\mathrm{n}$ & $\%$ \\
\hline $\mathbf{2 1}$ & 0 & 0 & 1 & 2.6 & 0 & 0 & 0 & 0 \\
\hline $\mathbf{1 2}$ & 1 & 12.5 & 3 & 7.7 & 4 & 3.9 & 6 & 11.3 \\
\hline $\mathbf{2 2}$ & 3 & 37.5 & 3 & 7.7 & 6 & 5.8 & 0 & 0 \\
\hline $\mathbf{1 5}$ & 1 & 12.5 & 0 & 0 & 0 & 0 & 0 & 0 \\
\hline $\mathbf{2 5}$ & 0 & 0 & 0 & 0 & 2 & 1.9 & 0 & 0 \\
\hline
\end{tabular}

CLP = cleft lip and palate

$\mathrm{CL}=$ isolated cleft lip only

$\mathrm{BCLP}=$ complete bilateral cleft lip, alveolus, and palate

L-UCLP = left side, complete unilateral cleft lip, alveolus, and palate

R-UCLP = right side, complete unilateral cleft lip, alveolus, and palate

Table 8: The frequency of supernumerary in the permanent teeth of 231 CLP southern Chinese children.

\begin{tabular}{|l|c|c|c|c|}
\hline \multirow{2}{*}{ Type of supernumerary } & \multicolumn{2}{|c|}{ CLP } & \multicolumn{2}{c|}{ non-CLP } \\
\cline { 2 - 5 } & $\mathrm{n}$ & $\%$ & $\mathrm{n}$ & $\%$ \\
\hline Supplemental & 2 & 6.7 & 1 & 14.2 \\
\hline Conical & 27 & 90.0 & 6 & 85.8 \\
\hline Tuberculate & 1 & 3.3 & 0 & 0 \\
\hline
\end{tabular}

CLP = cleft lip and palate.

* Adapted from Primosch (1981)

Table 9: Frequency of different supernumerary tooth types in CLP and non-CLP children.

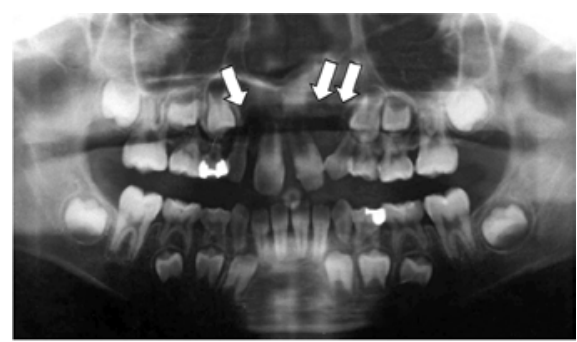

Figure 1: Missing permanent maxillary lateral incisor and canines.

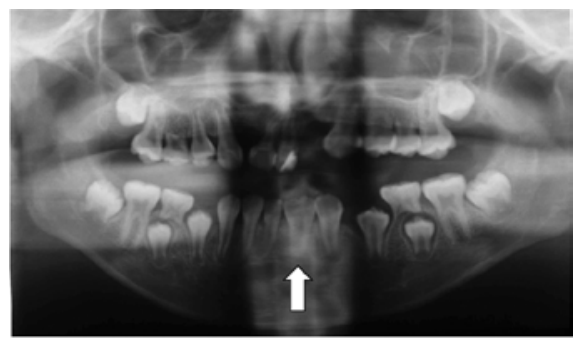

Figure 2: Double tooth involving the permanent mandibular left central and lateral incisors.

published report [21,34]. While most studies have found CP to occur most frequently in females an equal gender ratio was found in the present study, which is similar to that found by Menezes and Vieira [24] who studied 17 Caucasians with CP.

Other ethnic groups have been found to have higher prevalences of dental anomalies in CLP children than non-CLP children [1$4,8,10,12,23]$. However, the overall prevalence values obtained from this study can not be directly compared to the results of other studies as the prevalence figures reported in those studies refer to different types of dental anomalies found in the CLP subjects. Some of these studies reported on the general prevalence of anomalies in cleft subjects
$[2,10]$ whereas others concentrated on only one or two specific types of dental anomalies such as tooth number, size, shape, time of formation or eruption $[3,8,9,12]$. Moreover, some authors reported only dental anomalies that occurred in the anterior maxilla $[19,45]$ or on specific teeth $[9,18,28,45,61-65]$. Therefore, the figures from the present study are best compared with the published results for individual anomaly. Various factors such as the different characteristics of the samples in terms of size, age range, source of the sample, and the methodology may also influence the comparability of the results between this and other studies.

The prevalence figures of the various dental anomalies and their implications will be discussed independently.

\section{Hypodontia}

The $57.6 \%$ occurrence of hypodontia in the CLP children was lower than the 79\% reported by Carretero Quezada et al. [11]. However, in the children with only CL, the $37.5 \%$ prevalence of hypodontia was much higher than the $5.5 \%$ found by Olin [8] and the $21 \%$ by Jiroutova and Müllerova [66]. The discrepancy may be attributable at least partially to the small number of CL subjects in the present study. When the data for BCLP and UCLP were pooled together, the prevalence of hypodontia $(61.5 \%)$ was higher at $29.5 \%$ than reported by Jiroutova and Müllerova [66], and the $26.6 \%$ by Olin [8]. The prevalence of hypodontia (32.1\%) for the CP group in this study was remarkably similar to the $32.3 \%$ reported by Böhn [14] for 31 Danish and Norwegian children and with the $31.5 \%$ quoted by Ranta [9] for a group of 251 Finnish children.

The present study confirms that the maxillary lateral incisors are the most frequently missing teeth in CLP subjects $[8,14,16,21,67]$. The prevalence of missing permanent lateral incisors on the cleft side of children with UCLP (48.3\%), was similar to that (42.6\%) reported by Hellquist et al. [17].

In the present study, the prevalence of missing teeth on the non-cleft side of CLP children (51.3\%) was approximately seven times greater than for the non-CLP children (7.4\%). In CL children the prevalence

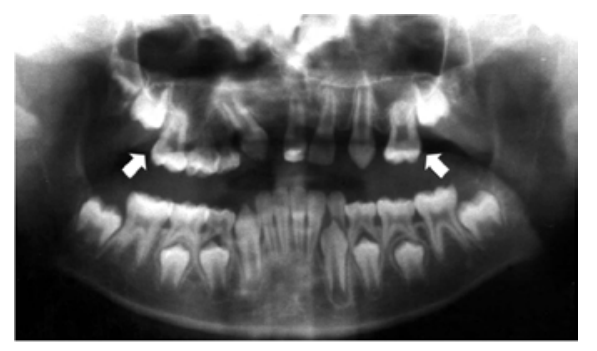

Figure 3: Taurodontism of permanent maxillary first molars.

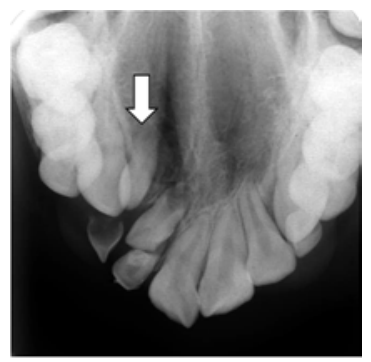

Figure 4: A conical shaped supernumerary tooth in relation to permanent maxillary right canine. 


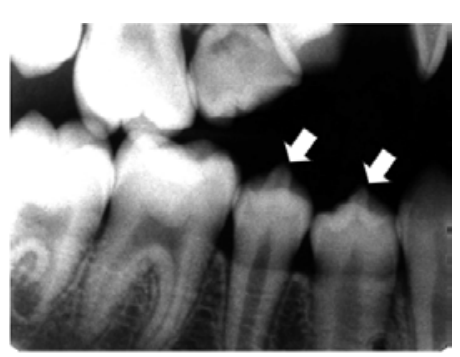

Figure 5: Dens evaginatus on mandibular right premolars.

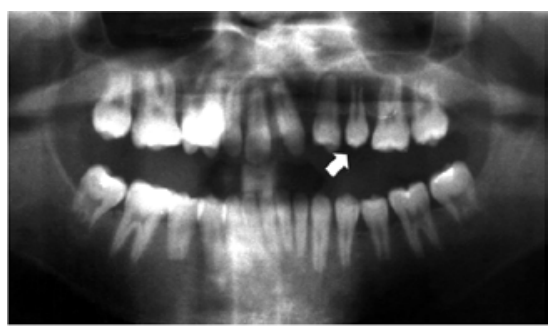

Figure 6: Microdontic maxillary left second premolar.

of missing teeth $(37.5 \%)$ was higher than the $4.5 \%$ for Danish and Norwegian children [14], the $5.2 \%$ for Swedish subjects [17], and $10.1 \%$ for Finnish children [68]. The prevalence of hypodontia in the noncleft region of UCLP children was 33.3\% which is in the range of $28 \%$ to $48.8 \%$ reported by Böhn [14], Hellquist et al. [17], and Ranta [68]. Similarly, the prevalence (41\%) of hypodontia in BCLP was within the $17.9 \%$ to $68.4 \%$ range quoted by Böhn [14] and Ranta [68]. When children with CP alone are considered, the finding from this study (32.1\%) is similar to that of Böhn [14], but much higher than the $22.7 \%$ reported by Olin [8].

In the non-cleft region of the maxilla, the lateral incisors were the most frequently missing teeth $(19.9 \%)$, followed by the maxillary (7.8\%) and mandibular (7.6\%) second premolars. Similar findings have been obtained in other studies $[8,14,17,68]$. The prevalence of hypodontia in the non-cleft region is said to increase with the severity of cleft $[14,16,24,68,69]$ this tendency occurred in this study.

\section{Supernumerary teeth}

In the present study, the prevalence of supernumerary teeth (10\%) in the permanent dentition was much lower than for hypodontia (57.6\%) in the CLP children, which implies that the permanent tooth germs are more susceptible to irreversible damage than to splitting. In CL children where the alveolus was apparently intact, the tooth germs of supernumeraries and lateral incisors could be expected to be less affected by the clefting. This may account for the higher frequency of supernumeraries in the CL group than any other cleft type. In other words, there is a tendency for the frequency of supernumeraries to decrease with the severity of cleft, a finding that has been previously reported [14].

The number of supernumerary teeth per individual in the non-cleft region was higher for the CLP than the non-CLP children although the difference was not statistically significant. This result implies that a factor, other than that of the cleft influences the formation of supernumeraries in CLP children. As no published literature exists on this topic, it is difficult to verify or compare this observation.

While most authors have considered the cleft as being the aetiological factor responsible for supernumerary teeth in CLP subjects [25], the hypotheses for the aetiology of hyperdontia in normal subjects may also be applicable to CLP subjects. The most popular hypothesis is localised hyperactivity of the dental lamina [57,70-72]. Other postulates include the expression of an atavistic trait, polygenetic reversion [7274], activation of the remaining clumps of epithelium following the break down of the primary epithelial band leading to tooth formation $[73,74]$; hyperactivity of the ectomesenchyme or neuroectoderm [74] and the formation of extra tooth buds or splitting of existing ones $[72,73]$.

\section{Taurodontism}

The reported rates of taurodontism in normal populations vary from $0.6 \%$ to $11.3 \%$ [31,75-78] while the prevalence of this trait is higher in association with hypodontia [32,79]. The occurrence rates in the CLP $(8.7 \%)$ and non-CLP (4.3\%) children in this study were within the range for normal non-Chinese subjects, but much lower than the 46.3\% found by MacDonald et al. [33] in a none random sample of non-CLP southern Chinese people, and 70.5\% in CLP Jordanians [21]. The use of different diagnostic criteria for taurodontism probably also contribute to this variation.

\section{Double tooth}

Double tooth occurred in $0.4 \%$ of the CLP children which was within the range $(0.1 \%-0.8 \%)$ for normal Chinese children [48]. Yuen et al. [40] believed that the double tooth in normal children arose from unseparated, rather than fused tooth masses. While Sawyer [80] thought that germination could result from either the splitting of a tooth germ during development or from fusion of a normal tooth bud with a developing supernumerary tooth. The occurrence of double teeth in CLP subjects can be explained by the incomplete splitting of tooth buds within the cleft region by the cleft inducing factor. The tooth buds could be those of a lateral incisor or a supernumerary tooth. Alternatively, it has been suggested that the dental lamina on each side of the fissure between the premaxilla and maxillary process may independently have the potential to form a lateral incisor tooth [81]. Under normal circumstances, the two adjacent tooth germs unite and proliferate as one tooth unit. However, an incomplete union would result in a double tooth. Therefore, a double tooth in the cleft region could be the result of an abortive union of normal lateral incisors. Another possibility for double tooth formation may be the fusion of a normal lateral incisor with a supernumerary tooth in the cleft region.

\section{Dens evaginatus}

Dens evaginatus has been reported to occur in $4.7 \%$ of non-CLP southern Chinese children [48], which is more than the 1.3\% (CLP) and $0 \%$ (non-CLP) found in this study. The sample size in this study may not have been big enough to indicate the prevalence of this relatively rare anomaly.

\section{Microdontia}

The higher prevalence of microdontia in the CLP children (42.4\%) than in the non-CLP children (0.9\%) in this study was not only due to the high percentage of peg-shaped laterals in the cleft region, but also due to the higher number of microdontic teeth in the non-cleft region, as found in other studies $[2,10,15,26,82]$. In this regard it has been suggested that genetic factors and corrective surgery of the cleft are related to the diminution of tooth size in CLP subjects $[60,83,84]$. A generalised decrease in tooth size for the whole dentition was not observed generalized in this study, therefore, it can be speculated that the genetic impact on tooth size may only be partial. 
Citation: Wong HM, Lai MC, King NM (2012) Dental Anomalies in Chinese Children with Cleft Lip and Palate. Dentistry 2:127. doi:10.4172/21611122.1000127

\section{Conclusions}

This group of Chinese CLP children exhibited the various types of dental anomalies. Statistically higher prevalences of hypodontia, supernumerary teeth and microdontia were demonstrated in the CLP children than in the non-CLP children. Further studies of dental anomalies and traits in CLP children of various ethnic origins are required to facilitate future comparisons and ultimately a better understanding of their aetiology and relationship to the cleft defect.

\section{References}

1. Curtis EJ, Fraser FC, Warburton D (1961) Congenital cleft lip and palate. Am J Dis Child 102: 105-109.

2. Jordan RE, Kraus BS, Neptune CM (1966) Dental abnormalities associated with cleft lip and/or palate. Cleft Palate J 3: 22-55.

3. Fishman LS (1970) Factors related to tooth number, eruption time, and tooth position in cleft palate individuals. ASDC J Dent Child 37: 303-306.

4. Haring FN (1976) Dental development in cleft and noncleft subjects. Angle Orthod 46: 47-50.

5. Helióvaara A, Ranta R, Rautio J (2004) Dental abnormalities in permanent dentition in children with submucous cleft palate. Acta Odontol Scand 62: 129131

6. Lai MC, King NM, Wong HM (2008) Dental development of Chinese children with cleft lip and palate. Cleft Palate Craniofac J 45: 289-296.

7. Camporesi M, Baccetti T, Marinelli A, Defraia E, Franchi L (2010) Maxillary dental anomalies in children with cleft lip and palate: a controlled study. Int $J$ Paediatr Dent 20: 442-450.

8. Olin WH (1964) Dental anomalies in harelip and cleft palate patients. Angle Orthod 34: 119-123.

9. Ranta R (1983) Hypodontia and delayed development of the second premolars in cleft palate children. Eur J Orthod 5: 145-148.

10. Kraus BS, Jordan RE, Pruzansky S (1966) Dental anomalies in the deciduous and permanent dentition of individual with cleft lip and palate. J Dent Res 45: 1736-1746.

11. Carretero Quezada MG, Hoeksma JB, van de Velde JP, Prahl-Andersen B Kuijpers-Jagtman AM (1988) Dental anomalies in patients with familial and sporadic cleft lip and palate. J Biol Buccale 16: 185-190.

12. Schroeder DC, Green LJ (1975) Frequency of dental trait anomalies in cleft, sibling, and noncleft groups. J Dent Res 54: 802-807.

13. Bixler D (1981) Genetics and clefting. Cleft Palate J 18: 10-18.

14. Boehn A (1963) Dental anomalies in harelip and cleft palate. Acta Odontol Scand 21: 1-109.

15. Dixon DA (1966) Abnormalities of the teeth and supporting structures in children with clefts of lip and palate. In: The Causes and Natural History of Cleft Lip and Palate, ed. Drillien CM, Ingram TTS, Wilkinson EM, E. \& S. Livingstone Ltd, Edinburgh \& London.

16. Ranta R (1972) The development of the permanent teeth in children with complete cleft lip and palate. Thesis. Proc Finn Dent Soc 1972.

17. Hellquist R, Linder-Aronson S, Norling M, Ponten B, Stenberg T (1979) Dental abnormalities in patients with alveolar clefts, operated upon with or without primary periosteoplasty. Eur J Orthod 1: 169-180.

18. Suzuki A, Takahama Y (1992) Maxillary lateral incisors of subjects with cleft lip and/or palate: Part I. Cleft Palate Craniofac J 29: 377-379.

19. Vichi M, Franchi L (1995) Abnormalities of the maxillary incisors in children with cleft lip and palate. ASDC J Dent Child 62: 412-417.

20. Haavikko K (1971) Hypodontia of permanent teeth. An orthopantomographic study. Suom Hammaslaak Toim 67: 219-225.

21. Al Jamal GA, Hazza'a AM, Rawashdeh MA (2010) Prevalence of dental anomalies in a population of cleft lip and palate patients. Cleft Palate Craniofac J 47: 413-420.

22. Schneider EL (1973) Lip pits and congenital absence of second premolars: varied expression of the Lip Pits syndrome. J Med Genet 10: 346-349.
23. Ranta R, Stegars T, Rintala AE (1983) Correlations of hypodontia in children with isolated cleft palate. Cleft Palate J 20: 163-165.

24. Menezes R, Vieira AR (2008) Dental anomalies as part of the cleft spectrum Cleft Palate Craniofac J 45: 414-419.

25. Millhon JA, Stafne EC (1941) Incidence of supernumerary and congenitally missing incisor teeth in eighty-one cases of harelip and cleft palate. Am J Orthod and Oral Surg 27: 599-604.

26. Dixon DA (1968) Defects of structure and formation of the teeth in persons with cleft palate and the effect of reparative surgery on the dental tissues. Oral Surg Oral Med Oral Pathol 25: 435-446.

27. Lauterstein AM, Pruzansky S (1969) Tooth anomalies in the oral-facial-digital syndrome. Teratology 2: 137-145.

28. Woolf CM, Woolf RM, Broadbent TR (1965) lateral incisor anomalies microforms of cleft lip and palate? Plast Reconstr Surg 35: 543-547.

29. Mills LF, Niswander JD, Mazaheri M, Brunelle JA (1968) Minor oral and facia defects in relatives of oral cleft patients. Angle Orthod 38: 199-204.

30. Tolarová M (1969) Microforms of cleft lip and-or cleft palate. Acta Chir Plast 11: 96-107.

31. Holt RD, Brook AH (1979) Taurodontism: a criterion for diagnosis and its prevalence in mandibular first permanent molars in a sample of 1,115 British schoolchildren. J Int Assoc Dent Child 10: 41-47.

32. Schalk-van der Weide Y, Steen WH, Bosman F (1993) Taurodontism and length of teeth in patients with oligodontia. J Oral Rehabil 20: 401-412.

33. MacDonald-Jankowski DS, Li TT (1993) Taurodontism in a young adult Chinese population. Dentomaxillofac Radiol 22: 140-144.

34. Akcam MO, Evirgen S, Uslu O, Memikoğlu UT (2010) Dental anomalies in individuals with cleft lip and/or palate. Eur J Orthod 32: 207-213.

35. Duncan WK, Helpin ML (1987) Bilateral fusion and gemination: a literature analysis and case report. Oral Surg Oral Med Oral Pathol 64: 82-87.

36. Grahnén H, Granath LE (1961) Numerical variations in primary dentition and their correlation with the permanent dentition. Odontol Revy 12: 348-357.

37. Ravn JJ (1971) Aplasia, supernumerary teeth and fused teeth in the primary dentition. An epidemiologic study. Scand J Dent Res 79: 1-6.

38. Gellin ME (1984) The distribution of anomalies of primary anterior teeth and their effect on the permanent successors. Dent Clin North Am 28: 69-80.

39. Razak IA, Nik-Hussein NN (1986) A retrospective study of double teeth in the primary dentition. Ann Acad Med Singapore 15: 393-396

40. Yuen SW, Chan JC, Wei SH (1987) Double primary teeth and their relationship with the permanent successors: a radiographic study of 376 cases. Pediat Dent 9: 42-48.

41. Hagman FT (1988) Anomalies of form and number, fused primary teeth, correlation of the dentitions. ASDC J Dent Child 55: 359-361.

42. Saito $T$ (1959) A genetic study on the degenerative anomalies of deciduous teeth. Jpn J Hum Genet 4: 27-53.

43. Niswander JD, Sujaku C (1963) Congenital anomalies of teeth in japanese children. Am J Phys Anthropol 21: 569-574.

44. Barac-Furtinovic V, Skrinjaric I (1991) [Double teeth in primary dentition and findings of permanent successors]. Acta Stomatol Croat 25: 39-43.

45. Pöyry M, Ranta R (1985) Anomalies in the deciduous dentition outside the cleft region in children with oral clefts. Proc Finn Dent Soc 81: 91-97.

46. Yip WK (1974) The prevalence of dens evaginatus. Oral Surg Oral Med Oral Pathol 38: 80-87.

47. Goto T, Kawahara K, Kondo T, Imai K, Kishi K, et al. (1979) Clinical and radiographic study of dens evaginatus. Dentomaxillofac Radiol 8: 78-83.

48. King NM, Tsai JSJ, Wong HM (2010) Morphological and numerica characteristics of the southern Chinese dentitions. Part I: Anomalies in the permanent dentition. Open Anthropol J 3: 54-64.

49. Yumikura S, Toshida K (1936) Abnormal cusp on the occusal surface of the human premolar. Kokubyo Gakkai Zasshi 10: 73

50. Chen RS (1984) Conservative management of dens evaginatus. J Endod 10 253-257. 
Citation: Wong HM, Lai MC, King NM (2012) Dental Anomalies in Chinese Children with Cleft Lip and Palate. Dentistry 2:127. doi:10.4172/21611122.1000127

51. Hill FJ, Bellis WJ (1984) Dens evaginatus and its management. Br Dent J 156: 400-402.

52. Loh HS, Lim SS (1985) Facial infection arising from dens evaginatus. Br Dent J 158: 367-368.

53. Nik-Hussein NN (1986) Apexification of a non-vital dens evaginatus premolar. J Pedod 11: 91-97.

54. Lin LM, Chance K, Skribner J, Langeland K (1987) Dens evaginatus: a case report. Oral Surg Oral Med Oral Pathol 63: 86-89.

55. Ju Y (1991) Dens evaginatus--a difficult diagnostic problem? J Clin Pediatr Dent 15: 247-248.

56. Echeverri EA, Wang MM, Chavaria C, Taylor DL (1994) Multiple dens evaginatus: diagnosis, management, and complications: case report. Pediatr Dent 16: 314-317.

57. Primosch RE (1981) Anterior supernumerary teeth--assessment and surgical intervention in children. Pediatr Dent 3: 204-215.

58. Ling LYK (1992) A morphometric study of the dentition of 12 year old Chinese children in Hong Kong. PhD Thesis, The University of Hong Kong.

59. Landis JR, Koch GG (1977) The measurement of observer agreement for categorical data. Biometrics 33: 159-174.

60. Sofaer JA (1979) Human tooth-size asymmetry in cleft lip with or without cleft palate. Arch Oral Biol 24: 141-146.

61. Ranta R (1971) The effect of congenital cleft lip, alveolar process and palate on the tooth germ of the lateral incisor and on its position in relation to the cleft. An orthopantomyographic study. Suom Hammaslaak Toim 67: 295-301.

62. Ranta R (1971) On the development of central incisors and canines situated adjacent to the cleft in unilateral total cleft cases. An orthopantomographic and clinical study. Suom Hammaslaak Toim 67: 345-349.

63. Ranta R (1971) Eruption of the premolars and canines and factors affecting it in unilateral cleft lip and palate cases. An orthopantomographic study. Suom Hammaslaak Toim 67: 350-355

64. Ranta R (1983) Developmental course of 27 late-developing second premolars. Proc Finn Dent Soc 79: 9-12.

65. Suzuki A, Watanabe M, Nakano M, Takahama Y (1992) Maxillary lateral incisors of subjects with cleft lip and/or palate: Part 2. Cleft Palate Craniofac J 29: $380-384$

66. Jiroutová O, Müllerová Z (1994) The occurrence of hypodontia in patients with cleft lip and/or palate. Acta Chir Plast 36: 53-56.

67. Harvold E (1947) Observation on the development of the upper jaw by hair lip and cleft palate. Odont T 55: 289-305
68. Ranta R (1986) A review of tooth formation in children with cleft lip/palate. Am J Orthod Dentofacial Orthop 90: 11-18.

69. Ranta R, Rintala A (1984) Separate clefts of the lip and the palate. A variant of cleft lip and palate. Scand J Plast Reconstr Surg 18: 233-235.

70. Humerfelt D, Hurlen B, Humerfelt S (1985) Hyperdontia in children below four years of age: a radiographic study. ASDC J Dent Child 52: 121-124.

71. McKibben DR, Brearley LJ (1971) Radiographic determination of the prevalence of selected dental anomalies in children. ASDC J Dent Child 28: 390-398.

72. Huang WH, Tsai TP, Su HL (1992) Mesiodens in the primary dentition stage: a radiographic study. ASDC J Dent Child 59: 186-189.

73. Yusof WZ (1990) Non-syndrome multiple supernumerary teeth: literature review. J Can Dent Assoc 56: 147-149.

74. Kessler HP, Kraut RA (1989) Dentigerous cyst associated with an impacted mesiodens. Gen Dent 37: 47-49.

75. Keene HJ (1966) A morphologic and biometric study of taurodontism in a contemporary population of 1200 young adult Israeli patients. Am J Phys Anthropol 25: 208-209.

76. Blumberg JE, Hylander WL, Goepp RA (1971) Taurodontism: a biometric study. Am J Phys Anthropol 34: 243-255.

77. Shifman A, Chanannel I (1978) Prevalence of taurodontism found in radiographic dental examination of 1,200 young adult Israeli patients. Community Dent Ora Epidemiol 6: 200-203.

78. Ruprecht A, Batniji S, el-Neweihi E (1987) The incidence of taurodontism in dental patients. Oral Surg Oral Med Oral Pathol 63: 743-747.

79. Seow WK, Lai PY (1989) Association of taurodontism with hypodontia: a controlled study. Pediatric Dent 11: 214-219.

80. Sawyer DR (1992) Developmental disorders of the teeth. In: Prabhu SR, Wilson DF, Daftary DK, Johnson NW, eds. Oral diseases in the Tropics. Oxford: Oxford University Press 543-548.

81. Oee T (1957) On the early development of human dental lamina. Okajimas Folia Anat Jpn 30: 198-210.

82. Lai MC, King NM, Wong HM (2009) Abnormalities of maxillary anterior teeth in Chinese children with cleft lip and palate. Cleft Palate Craniofac J 46: 58-64.

83. Garn SM, Lewis AB, Vicinus JH (1963) Third molar polymorphism and its significance to dental genetics. J Dent Res 42: s1344-s1363.

84. Adams MS, Niswander JD (1967) Developmental 'noise' and a congenita malformation. Genet Res 10: 313-317. 